\title{
EXPERIMENTAL STUDY OF THE EFFECT OF THERMAL DAMAGE ON RESISTIVITY AND MECHANICAL PROPERTIES OF SANDSTONE
}

\author{
Weiqiang ZHANG *, Qiang SUN *, Shuqing HAO and Lining YANG
}

School of Resources and Geosciences, China University of Mining and Technology, Xuzhou, Jiangsu Province 221116, P.R. China

*Corresponding author's e-mail: zhangweiqiang1204@163.com; sunqiang04@126.com.

\begin{tabular}{l} 
ARTICLE INFO \\
\hline Article history: \\
Received 1 July 2015 \\
Accepted 9 December 2015 \\
Available online 18 December 2015 \\
\hline Keywords: \\
Resistivity \\
Sandstone \\
Thermal damage \\
Uniaxial compressive strength \\
Porosity
\end{tabular}

\begin{abstract}
In order to study the effect of thermal damage caused by heating on resistivity of rocks, uniaxial compressive experiment was conducted on sandstone samples after heating treatment at different temperatures (from $25{ }^{\circ} \mathrm{C}$ to $900{ }^{\circ} \mathrm{C}$ ), and the resistivity of samples was tested in the whole loading process. After then, mercury injection experiment test was carried on the failed samples. Consequently, the relationship between resistivity, stress, porosity and derivative thermo gravimetric of samples was obtained. The experimental results showed that: (1) The resistivity of rock increased gradually with increasing load while the discreteness of the resistivity value occurred from $300{ }^{\circ} \mathrm{C}$; (2) With the heating temperature increase, the strength of rock gradually decreases. Conversely, the initial resistivity, porosity and peak strain gradually increase; (3) There is a threshold temperature around $300{ }^{\circ} \mathrm{C}$ of sandstone samples which the physical and mechanical properties will change rapidly when the temperature exceed it. This study would be valuable to the identification of precursor information for thermal disasters in rock engineering.
\end{abstract}

\section{INTRODUCTION}

Rock damage caused by heat needs to be considered in dealing with many rock engineering problems in the high-temperature environment, such as nuclear waste storage (Sundberg et al., 2009), underground coal gasification (Roddy and Younger, 2010; Sun et al., 2015a), geothermal resources development (Rutqvist et al., 2002; Zhang et al., 2015) and stability analysis, reinforcement and repair constructions in rocks after exposure to fire (Zhan and Cai, 2007). In the study of thermal damage of rock, the variation of thermo physical and mechanical properties of rock materials are required.

Resistivity is a direct physical parameter of rock conductive properties, which indicates the level of resistance when electrical current flows through a unit volume of medium. The higher the resistivity, the worse the conductivity of the rock is (Binley et al., 1996). The level of the rock resistivity mainly depends on the mineral composition, internal structure, porosity, water content, spatial distribution of cracks, stress state and temperature (Guseinov and Garatsev, 2005). Compared with other indirect parameters, such as strength, strain and deformation modulus, resistivity can reflect the internal state of rock better. Currently, the applications of resistivity in petrologic ally mainly focus on the electrical prospecting, anisotropy, moisture content, stress state and other aspects (Ferrero and Marini, 2001; Lebedev and Shepel, 1984). For example, the variation of apparent resistivity in coal mine water inrush was analyzed (Liu et al., 2009); the anisotropic changes of apparent resistivity of rock during the loading process was widely studied (Chen et al., 1987; Mao et al., 1988; Chen et al., 2003; Liao et al., 2003 analyzed the relationship between the anisotropy of the variation of dynamic rock resistivity and the change of water network conductive path caused by the extension of rock fracture through laboratory experiments, and then proposed a quantitative method of identifying the extending premonition of hidden fracture; the variation of the resistivity of water-saturated rock under uniaxial compression was studied (Brace, 1975 ), and the results showed that under $1 / 3$ to $2 / 3$ of the burst pressure during the loading process, the resistivity of saturated rock initially increased and then decreased rapidly.

The extensive studies referenced above show that resistivity can reflect the mechanical properties of rocks well, and it investigated the structural and mechanical properties of rocks from another aspect of the inherent properties of rock. However, research on the relationship between resistivity and thermal damage of rock is rare, and very few published reports on this topic have been found. Moreover, only limited data is found in the literature concerning the conductivity of rock mainly at room temperature, and there are few investigations into the effect of temperature on its electrical conductivity. This paper examines the relationship between rock thermal damage and resistivity through laboratory experiments, and the results could provide a fast method for the study of rock damage. 


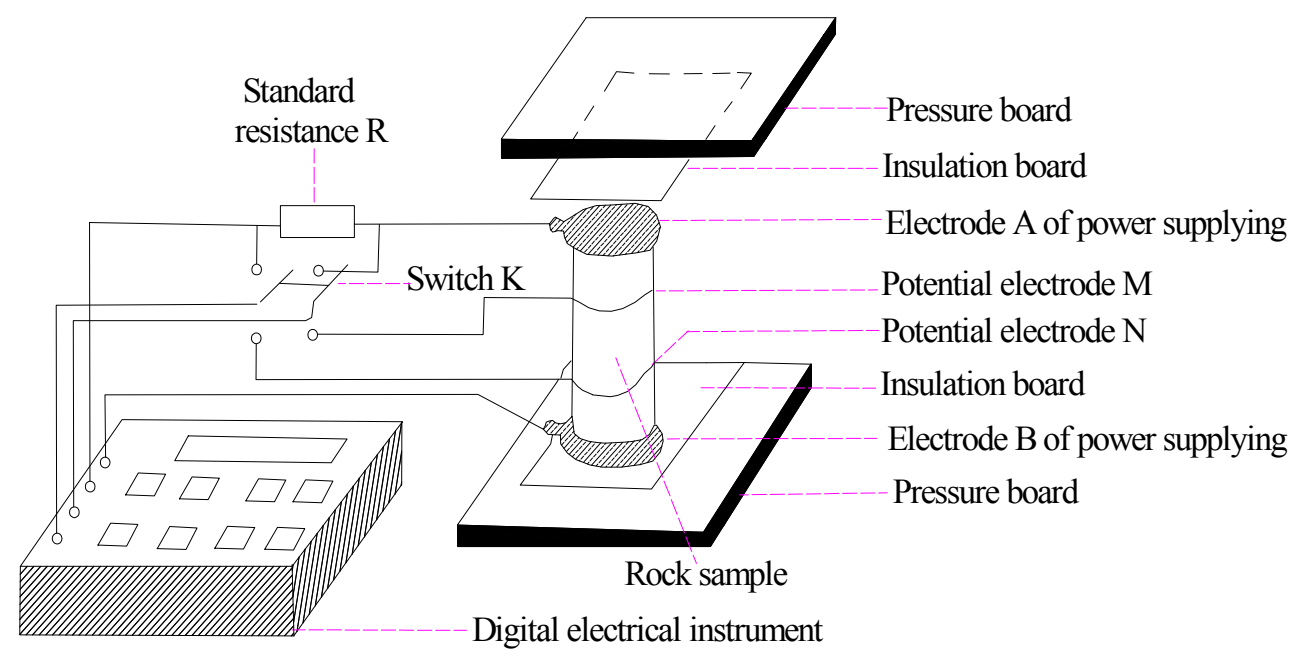

Fig. 1 Schematic diagram of the experimental system for stress and resistivity of rock samples under uniaxial compression (Sun et al., 2015b).

\section{EXPERIMENTS}

\subsection{THEORETICAL BASIS OF RESISTIVITY MEASUREMENT}

Resistivity is one of the inherent properties of rock material. It can be detected by measuring the electrical current $(I)$ passing through a rock sample and the voltage $(U)$ between its two reverse surfaces of samples, and the computational formula is

$\rho=\frac{U S}{I L}$

where $\rho$ is resistivity $(\Omega \cdot \mathrm{m}), U$ is voltage $(\mathrm{V}), S$ is the cross-sectional area of samples $\left(\mathrm{m}^{2}\right), I$ is electricity (A), $L$ is the distance between two electrodes ( $\mathrm{m})$.

Figure 1 shows the schematic diagram of the experimental system for measuring the stress and resistivity of rock samples under uniaxial compression.

\subsection{PREPARATION OF ROCK SAMPLES}

Sandstone samples, which are fine sandstone with bulk density of $2.42 \mathrm{~g} / \mathrm{cm}^{3}$ were collected from Linyi, Shandong Province, China, and they appeared kermesinus in color. X-ray diffraction (XRD) analysis showed that dolomite, quartz, kaolinite, feldspar and biotite are the main components (as shown in Figure 2). The chemical composition is shown in Table 1 and the micro-structure of the samples at room temperature is shown in Figure 3. As can be seen from Figure 3, the sample has relatively complete solid particles, and the filling of cracks between particles is good, there is a small amount of original fissuring. Before loading, the specimens were cut into normative $\Phi 50 \times 100 \mathrm{~mm}$ cylinders.

\subsection{TEST PROCEDURE AND INSTRUMENTS}

In this test, the specimens under the state of natural water were heated at ten sets of temperature level (i.e. $25{ }^{\circ} \mathrm{C}, 100{ }^{\circ} \mathrm{C}, 200{ }^{\circ} \mathrm{C}, 300{ }^{\circ} \mathrm{C}, 400{ }^{\circ} \mathrm{C}$, $500{ }^{\circ} \mathrm{C}, 600{ }^{\circ} \mathrm{C}, 700{ }^{\circ} \mathrm{C}, 800{ }^{\circ} \mathrm{C}$ and $900{ }^{\circ} \mathrm{C}$ ) (four

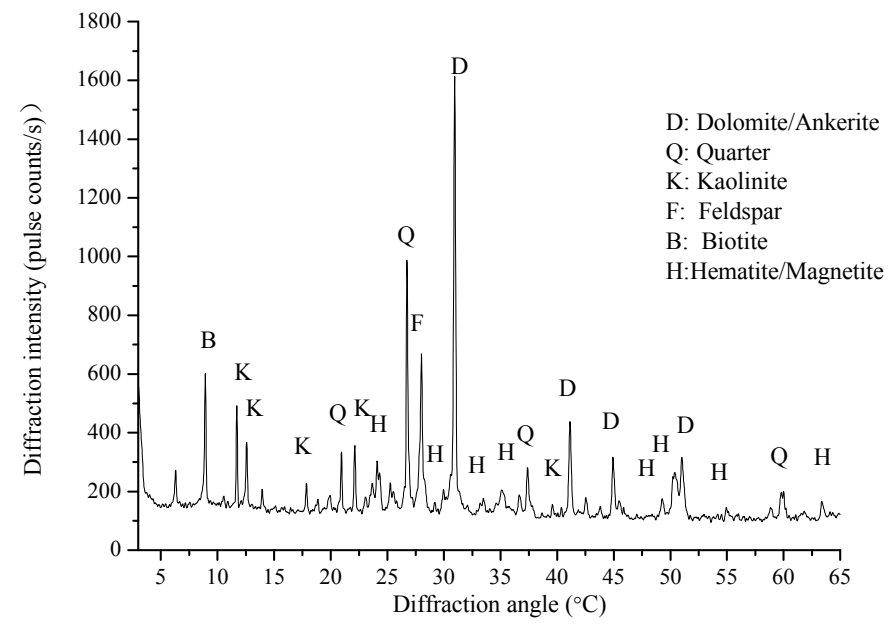

Fig. 2 XRD spectrum of sandstone sample (under $25^{\circ} \mathrm{C}$ ). 
Table 1 Chemical composition of sandstone sample.

\begin{tabular}{cccccccc}
\hline Sample type & $\mathrm{CO}_{2}$ & $\mathrm{MgO}$ & $\mathrm{Al}_{2} \mathrm{O}_{3}$ & $\mathrm{SiO}_{2}$ & $\mathrm{~K}_{2} \mathrm{O} / \mathrm{Na}_{2} \mathrm{O}$ & $\mathrm{CaO}$ & $\mathrm{Fe}_{2} \mathrm{O}_{3}$ \\
\hline Sandstone & $22.64 \%$ & $8.10 \%$ & 10.55 & 35.49 & $2.96 \%$ & $13.43 \%$ & $5.53 \%$ \\
\hline
\end{tabular}

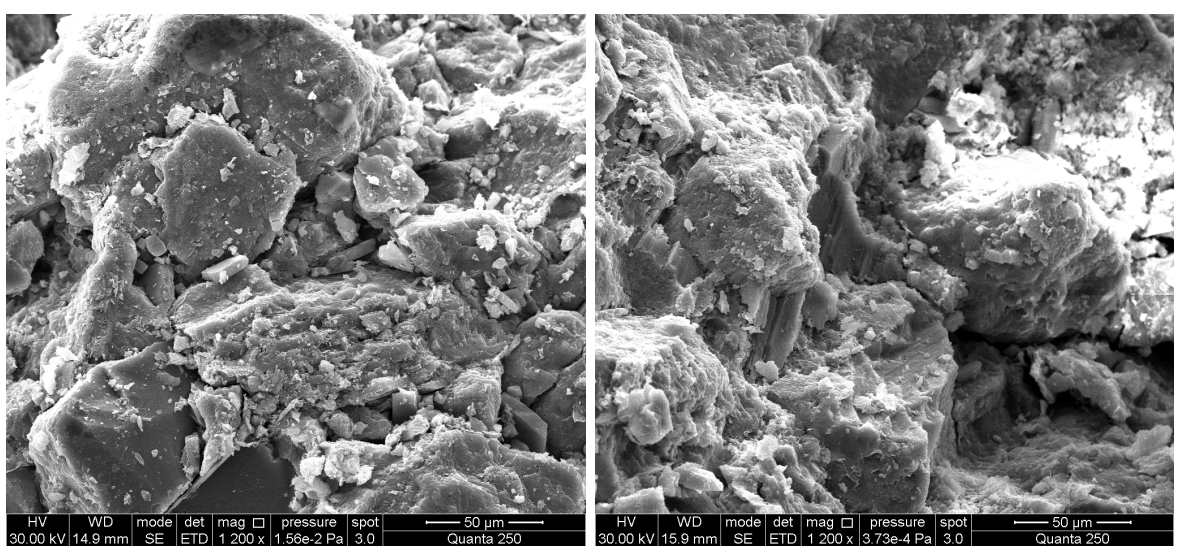

Fig. 3 Scanning electronic microscopy images of sandstone (at room temperature).

samples for a set) in a high temperature furnace (CTM300A, shown in Figure 4 (a)). Firstly, the rock specimens were heated at $5{ }^{\circ} \mathrm{C} / \mathrm{min}$ until the targeted temperature was reached. Secondly, the targeted temperature was held constant for $1 \mathrm{~h}$. Then, the furnace was cooled down to room temperature at $5{ }^{\circ} \mathrm{C} / \mathrm{min}$.

The uniaxial compressive strength test was carried on a WES-D1000 electro-hydraulic servo universal testing machine (the loading speed was $300 \mathrm{~N} / \mathrm{s}$, as shown in Figure 4 (b)) and the resistivity was tested in the whole loading process by a digital electrical instrument (DZD-6A, as shown in Figure 4 (c)). A quadrupole sounding mode was used in the resistivity experiment, and the line connection is shown in Figure1 (both ends of the rock sample and electrode is measured at the upper and lower ends, observe the potential difference between $\mathrm{MN}$ when the current passes through the rock sample). The uniaxial compressive strength and resistivity can be calculated by equation (2) and (3), respectively. Finally, the mercury injection experiment (using an AutoPore IV 9510 automatic mercury injection apparatus) and the derivative thermogravimetric analysis (DTG) test were carried out on the failed samples.

$\sigma_{c}=\frac{P}{A}$

where $\sigma_{c}$ is the uniaxial compressive strength (MPa), $P$ is the biggest failure load $(\mathrm{N})$, A is the crosssectional area of sample perpendicular to the loading direction $\left(\mathrm{mm}^{2}\right)$.

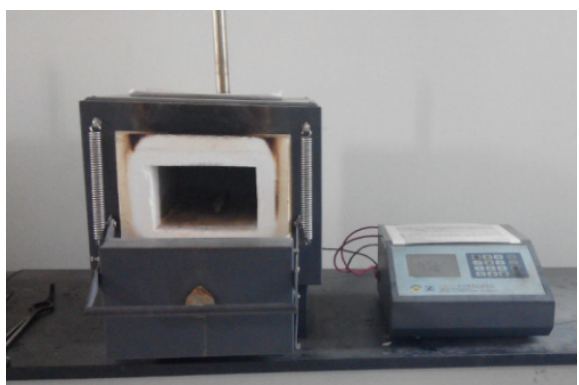

(a) CTM300A high temperature furnace

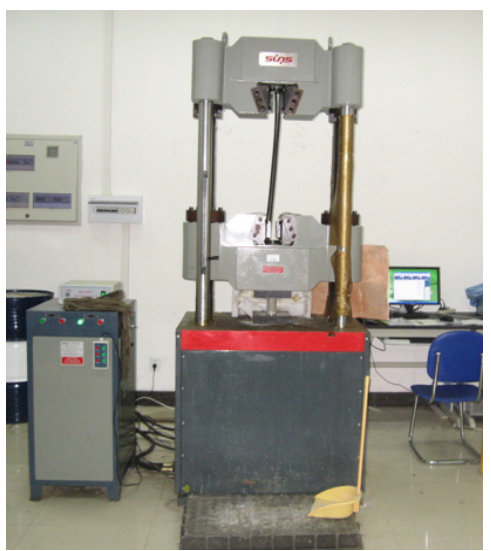

(b) WES-D1000 electro-hydraulic servo universal testing

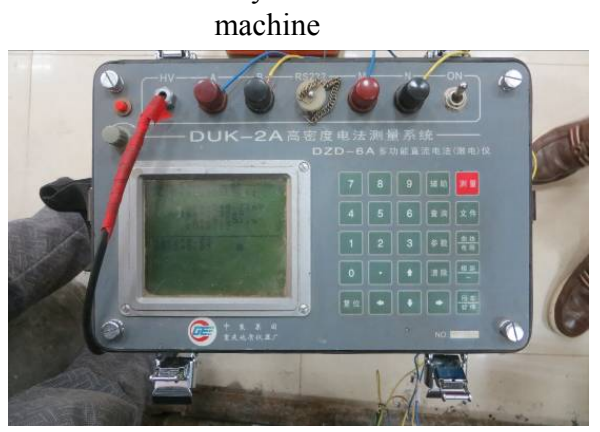
machine

(c) DZD-6A DC electrical meter

Fig. 4 The main experimental instruments. 
Table 2 The experimental results.

\begin{tabular}{|c|c|c|c|c|c|c|}
\hline \multirow[t]{2}{*}{$\mathrm{T} /{ }^{\circ} \mathrm{C}$} & \multicolumn{2}{|c|}{$\begin{array}{l}\text { Average initial } \\
\text { resistivity } / \Omega \cdot \mathrm{m}\end{array}$} & \multicolumn{2}{|c|}{ Standard deviation } & \multirow[t]{2}{*}{$\begin{array}{l}\text { Compressive } \\
\text { strength/MPa }\end{array}$} & \multirow[t]{2}{*}{ Porosity $/ \%$} \\
\hline & Values & Num. & Values & Num. & & \\
\hline 25 & 355 & 4 & 12.0 & 92 & 74 & 7.87 \\
\hline 100 & 441 & 4 & 19.1 & 80 & 77 & - \\
\hline 200 & 622 & 3 & 11.4 & 52 & 68 & 7.88 \\
\hline 300 & 933 & 4 & 11.0 & 84 & 72 & $8.26\left(340^{\circ} \mathrm{C}\right)$ \\
\hline 400 & 4229 & 4 & 1362 & 76 & 66 & 7.78 \\
\hline 500 & 10040 & 3 & 1874.8 & 48 & 60 & 9.24 \\
\hline 600 & 15318 & 4 & 2844.5 & 64 & 50 & 9.6 \\
\hline 700 & 17962 & 3 & 9547.9 & 52 & 51 & 10.34 \\
\hline 800 & 30272 & 4 & 15330.6 & 68 & 45 & 11.21 \\
\hline 900 & - & - & - & - & 33 & - \\
\hline
\end{tabular}

* Values are the values of parameters in table caption; Num. is the number of measurements used to calculate the parameter. The number of measurements which are used to calculate standard deviation was the sum of the number of samples' values in that temperature level.

$\rho=K \times \frac{\Delta U_{M N}}{I}$

where $K$ is a coefficient determined by device $(K=A / L), A$ is the cross-sectional area of rock sample, $L$ is the distance between $M N, \Delta U_{M N}$ is the potential difference between $\mathrm{MN}$ and $I$ is current.

\section{EXPERIMENTAL RESULTS AND ANALYSIS}

High temperature leads to the development of new micro-cracks, growth of pre-existing micro cracks, softening of internal structure, and escape of inside water. These changes may lead to the variation of physical and mechanical properties. Table 2 shows the experimental data of resistivity, stress, porosity and derivative thermo gravimetric of samples. The variation of resistivity and mechanical parameters were discussed in the following section.

\subsection{THE VARIATION OF INITIAL RESISTIVITY AND STANDARD DEVIATION}

Initial resistivity is an inherent attribute of rock, and it is a comprehensive index of many factors, such as internal structure, porosity, moisture content and the connectivity of cracks. After being treated at different high temperatures, the rock resistivity had an obvious increasing (shown in Figure 5), indicating that the electrical conductivity of rock was decreasing, especially when the temperature was above $300{ }^{\circ} \mathrm{C}$. Moreover, when the treated temperature was lower than $300{ }^{\circ} \mathrm{C}$, the value of initial resistivity (measured before loading) was relatively small (within $1000 \Omega \cdot \mathrm{m}$ ), while above $300{ }^{\circ} \mathrm{C}$, the initial resistivity increased sharply and reached $30.3 \times 10^{3} \Omega \cdot \mathrm{m}$ when the temperature was $800^{\circ} \mathrm{C}$.

The variation of the resistivity of sandstone is very different from that of the siderite ore, as shown in Figure 6. Note that for the siderite ore, the temperature dependence of resistivity also has a mutational point

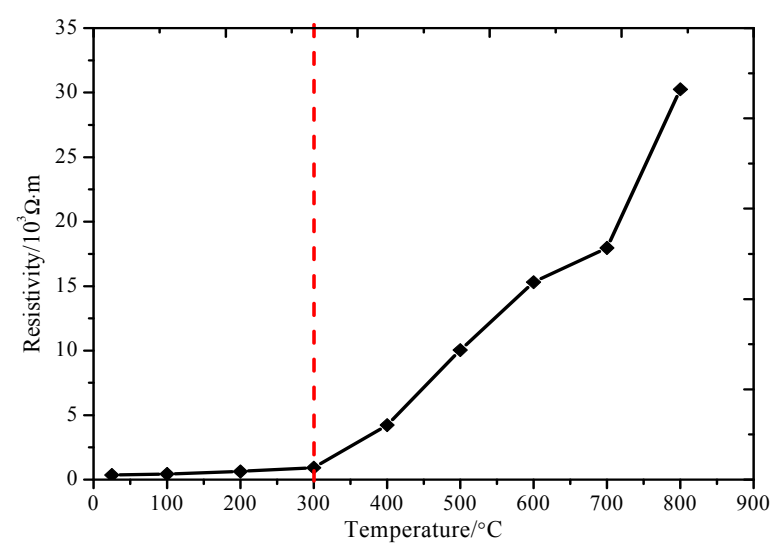

Fig. 5 The variation of initial resistivity of sandstone versus temperature (after cooled down to room temperature).

at around $350{ }^{\circ} \mathrm{C}$. Before this critical point, the specific conductance changes relatively little. However, when the temperature is higher than this critical point, there is a sharply decreasing. This difference may be caused by the different conductive mechanisms of the two kinds of samples and their different experimental conditions. Sandstone is a type of ion conductive material, while the siderite ore is a type of electrically conductive material. With the increase of heating temperature, the iron oxides, $\mathrm{FeO}$, $\mathrm{Fe}_{2} \mathrm{O}_{3}$ and $\mathrm{Fe}_{2} \mathrm{O}_{3} \cdot \mathrm{FeO}$ (have low resistivity), are formed inside the siderite ore, leading to fast decrease of resistivity of the siderite ore (Rzhevskii et al., 1965); Different states of water in sandstone evaporate gradually, causing the loss of active medium with conductive ions and then the increase of the resistivity of sandstone. The resistivity test of the siderite ore by Rzhevskii was conducted under the heating process, while the test of sandstone in this paper was done after the samples cooled down to room temperature. At high temperature, cracks have not developed yet and 


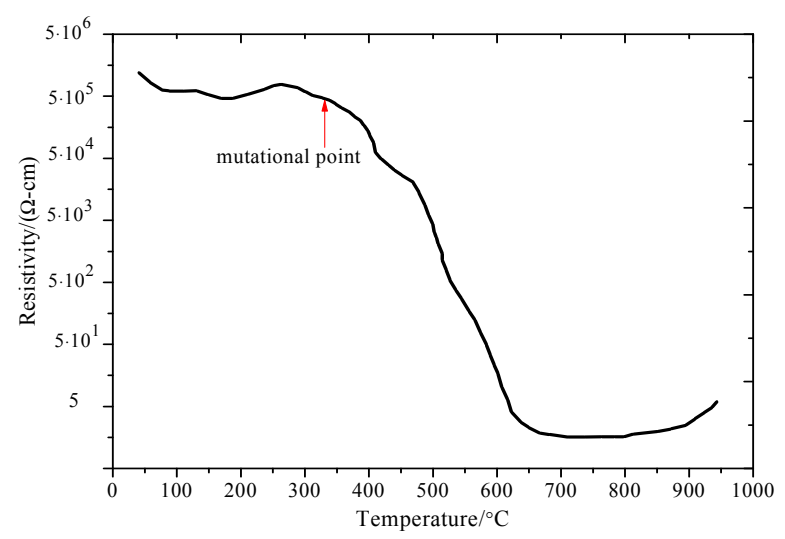

Fig. 6 Temperature dependence of resistivity of siderite ore (Rzhevskii et al., 1965) (under heating process).

the conductive ions can flow, leading to the resistivity of the siderite ore to decrease with the heating temperature; when the heated samples are cooled down, many cracks occur inside the rock and the conductive ions were limited, resulting in the increase of sandstone resistivity with heating temperature.

In the uploading process, the resistivity has a sudden drop first, and then keeps increasing. This is probably because in the beginning of uploading, rock sample is under the compression stage or elastic deformation stage, and in these two stages, the original pores were compressed or even enclosed, leading to internal structure of rock more compact and the resistivity declining. When the stress keeps increasing, the primary cracks expand continuously and new cracks exist. Weakening the compactness of internal structure and increasing the connectivity of cracks, resulting in the increases of resistivity.

Moreover, we found a very interesting phenomenon: the variation of resistivity versus stress showed a different trend below and above $300{ }^{\circ} \mathrm{C}$. Beside the first drop, the resistivity gradually increases with the stress increase lower than $300{ }^{\circ} \mathrm{C}$ while the change of resistivity expressed a big discreteness above $300{ }^{\circ} \mathrm{C}$. The higher the heating temperature, the larger the dispersion is, as shown in Figure 7 (the standard deviation of resistivity represents the degree of dispersion of the measured data, and which can be calculated by equation (4) and (5)). All of above shows that high temperature leads to the irreversible thermal damage of rock samples. The higher the heating temperature, the larger the damage is. The different patterns of variation of resistivity with temperature could be likely result from the brittle-to-plastic transition caused by the thermal damage of rock.

$$
\begin{aligned}
& \bar{\rho}=\frac{1}{N} \sum_{i=1}^{N} \rho_{i} \\
& D=\sqrt{\frac{1}{N} \sum_{i=1}^{N}\left(\rho_{i}-\bar{\rho}\right)^{2}}
\end{aligned}
$$

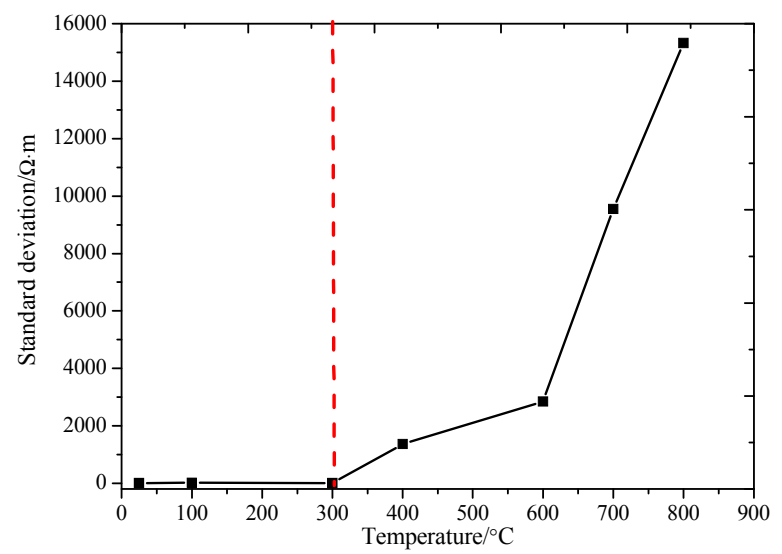

Fig. 7 Standard deviation of resistivity of samples under different temperatures.

where, $\bar{\rho}$ is the average resistivity $(\Omega \cdot \mathrm{m}) ; \rho_{i}$ is the resistivity in time $\mathrm{i}(\Omega \cdot \mathrm{m})$; $\mathrm{N}$ is the number of samples used to calculate; $D$ is the standard deviation of resistivity $(\Omega \cdot \mathrm{m})$.

\subsection{THE VARIATION OF PEAK STRENGTH AND PEAK STRAIN}

Figure 8 shows the variation of peak strength after being heated at different temperatures. When heating temperature is above $300{ }^{\circ} \mathrm{C}$, the peak strength decreases dramatically, and when the temperature reaches $600{ }^{\circ} \mathrm{C}$, the peak strength drops to $50 \mathrm{MPa}$ from $72 \mathrm{MPa}$ in $300{ }^{\circ} \mathrm{C}$. During $600{ }^{\circ} \mathrm{C} \sim 700^{\circ} \mathrm{C}$, the peak strength varies smoothly again, and then keeps declining sharply. In the temperature range from $300{ }^{\circ} \mathrm{C}$ to $900{ }^{\circ} \mathrm{C}$, the descending range of peak strength arrives to $54.2 \%$. As can be seen from the fitting curve, the variation of the peak strength of sandstone after heating in the temperature range of $25{ }^{\circ} \mathrm{C} \sim 900{ }^{\circ} \mathrm{C}$ can be described by a quadratic polynomial function, and the equation is

$$
\sigma=75.65-0.01 \times T-3.77 \times 10^{-5} \times T^{2}
$$

where $\sigma$ is the peak strength (MPa), $T$ is temperature $\left({ }^{\circ} \mathrm{C}\right)$. The correlation coefficient $\left(R^{2}\right)$ is 0.95 .

The thermal effect leads to the evaporation of internal water, reaction of minerals (such as decomposition, oxidation or phase transformation), weakening the connectivity of crystals, and changing the microstructure. These changes could result in the increases of defects and the decreases of strength.

At the same period, the thermal effect also leads to the variation of the peak strain, which can be shown in Figure 9. Note that with the increase of thermal treatment temperature, the peak strain of sandstone increases. This increase could be related to the increase of cracks due to thermal exposure. When the temperature is lower than $400{ }^{\circ} \mathrm{C}$, the change of peak strain is very small; when the heating temperature is above $400{ }^{\circ} \mathrm{C}$, the increase becomes very steeply. This increased deformation is very likely caused by the generation of micro-cracks during the heating process. 


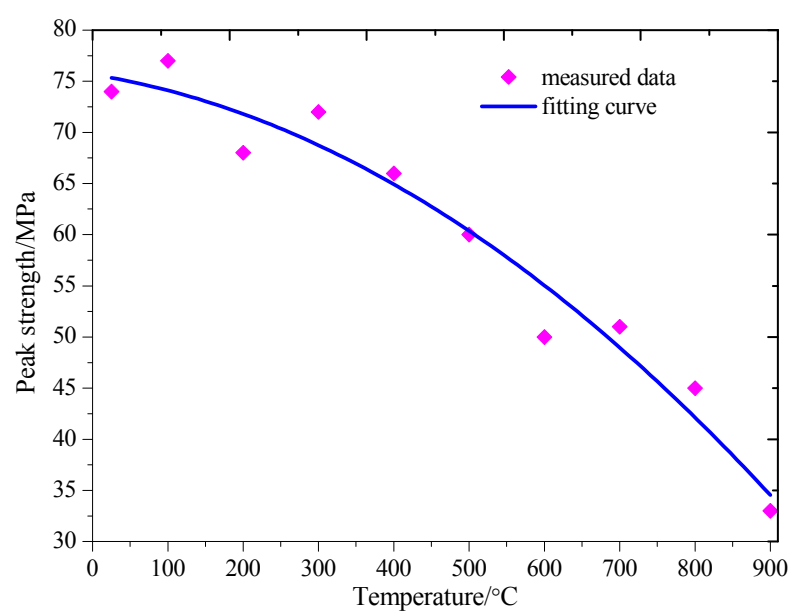

Fig. 8 The variation of peak strength of samples after heated.

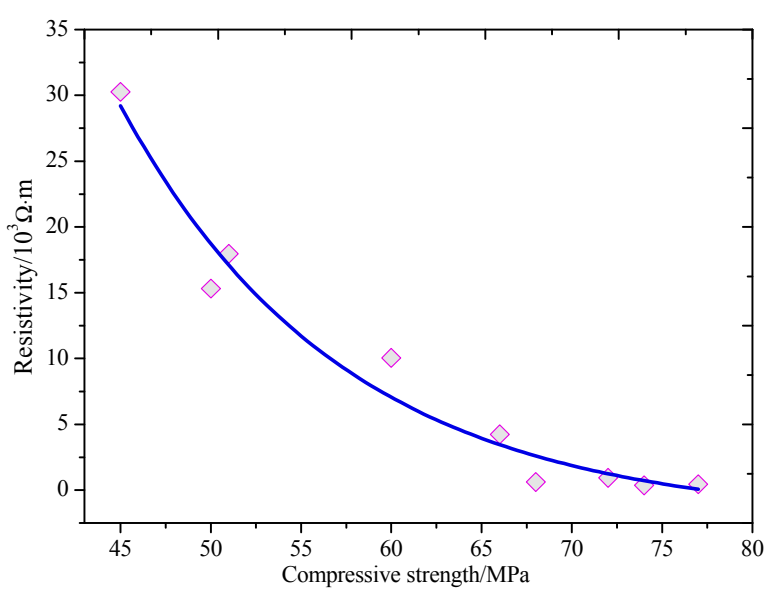

Fig. 10 The initial resistivity-strength curve of sandstone after heated.

\subsection{RELATIONSHIP BETWEEN INITIAL RESISTIVITY AND STRENGTH}

Figure 10 shows the variation of resistivity versus strength of sandstone samples after being heated at different temperature. The vertical axis represents the initial resistivity and the horizontal axis represents the strength as well. Experimental data showed that the relationship between initial resistivity and strength of sandstone after thermal treatment can be fitted as

$\rho_{0}=-2.28+1209.34 \times \exp \left(-\frac{\sigma}{12.34}\right)$

where $\rho_{0}$ is initial resistivity $(\Omega \cdot \mathrm{m}), \sigma$ is the strength (MPa), the correlation coefficient $\left(\mathrm{R}^{2}\right)$ is 0.96 .

Compressive strength is one important property of rock. However, it is very difficult to measure under the complex geological and environmental conditions, such as high temperature and deep underground condition. Equation (7) suggests that it could be estimated from the variation of rock resistivity.

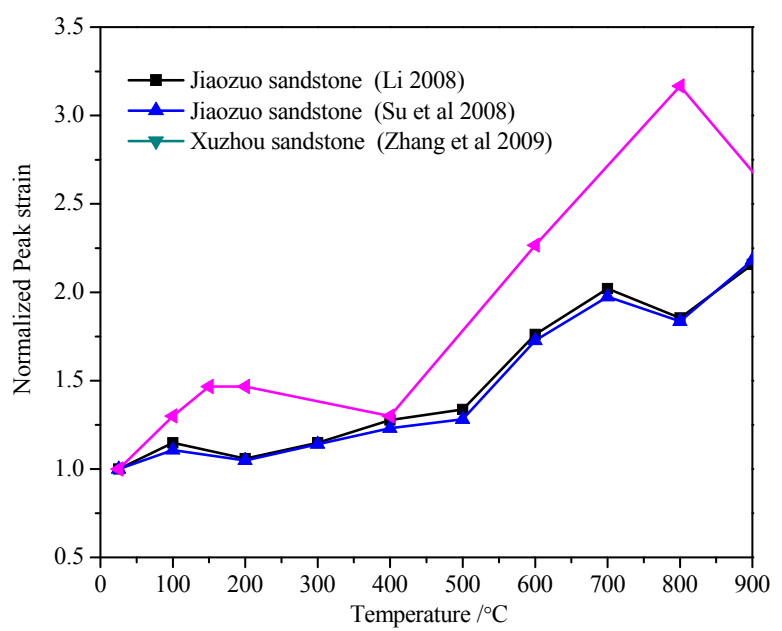

Fig. 9 The variation of peak strain of sandstone after heated.

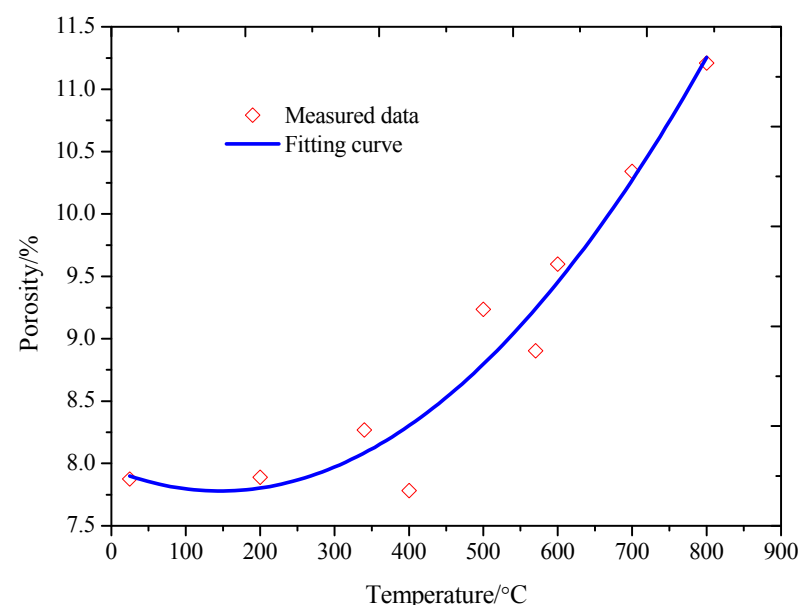

Fig. 11 The variation of porosity of sandstone under different temperatures.

\subsection{THE RELATIONSHIP BETWEEN INITIAL RESISTIVITY AND POROSITY}

The variation of porosity versus temperature of rock sample was measured through the mercury injection experiment, and the result is shown in Figure 11. In general, the porosity increases with heating temperature increases, and in the range of $25^{\circ} \mathrm{C} \sim 800{ }^{\circ} \mathrm{C}$, two phases can be divided according to the increase rate: (1) $25{ }^{\circ} \mathrm{C} \sim 400{ }^{\circ} \mathrm{C}$, the porosity of samples change very little; (2) $400{ }^{\circ} \mathrm{C} \sim 800{ }^{\circ} \mathrm{C}$, the porosity varies very fast, and when the temperature arrived at $800{ }^{\circ} \mathrm{C}$, the porosity has reached $11.21 \%$ (the coefficient of amplification is $44.03 \%$ ). The fitting curve of the porosity versus heating temperature can be expressed by equation (8).

$\phi=7.95-2.38 \times 10^{-3} T+8.14 \times 10^{-6} T^{2}$

where $\phi$ is the porosity (\%), $\mathrm{T}$ is the heating temperature $\left({ }^{\circ} \mathrm{C}\right)$.

A catastrophe point of the variation of porosity of sandstone samples was found around $400{ }^{\circ} \mathrm{C}$. When 


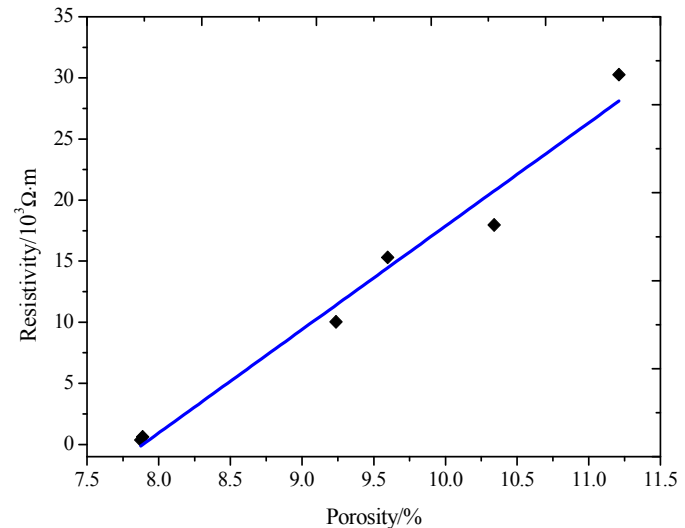

Fig. 12 The relationship of initial resistivity and porosity.

the heating temperature is lower than it, the major changes in sandstone are the variation of adsorbed water and interlayer water existing in extremely small pores. Because the porosity of samples changes subtly below $400{ }^{\circ} \mathrm{C}$, the macroscopic mechanical properties of rock have no obvious change in this temperature range. With the temperature continues increase, the activity of the medium between the particles and the plastic component of rock increases, leading to the brittle rock turns to ductile gradually, and the structure and composition of mineral are also altered. When the temperature is above $400{ }^{\circ} \mathrm{C}$, the mineral composition gradually emerges dehydration, phase transformation, the diffusion of hydroxyl, hydrogen or water inside the crystal, and the aggregation and hydrolysis in the end of micro-cracks. Moreover, other physical and chemical reactions also set off. All these factors lead to the development of micro cracks, the variation of pore structure, and the increase and improvement of fluid flow passages, making the porosity change faster.

Figure 12 shows the relationship between initial resistivity and porosity, and it indicates that the initial resistivity of sandstone samples increases with the porosity increases. The blue curve is the fitting curve of initial resistivity vs. porosity, suggesting that the variation of initial resistivity with porosity of the samples follows a linear function after hightemperature heating, and the mathematical equation is

$\rho_{0}=8.46 \times \Phi-66.77$

where $\rho_{0} \times 10^{3}$ is the initial resistivity $(\Omega \cdot \mathrm{m}), \Phi$ is porosity (\%). The correlation coefficient $\left(\mathrm{R}^{2}\right)$ is 0.97 .

\subsection{THE RELATIONSHIP OF INITIAL RESISTIVITY AND DTG}

A DTG curve represents the functional relationship between the change rate of sample mass versus time and temperature, and the equation can be expressed as:

$d m / d t=f(T)$

where $m$ is the variation of mass, $t$ is time, $T$ is heating temperature.

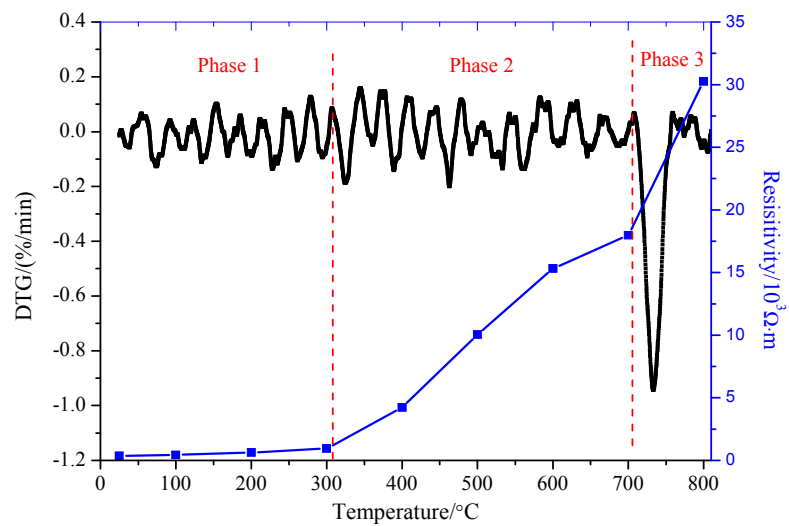

Fig. 13 The variation of initial resistivity and DTG versus temperature.

The peak points of DTG curve correspond to the maximum values of mass loss rate. The number of peak point is the number of weight loss, and the area covered by each peak is proportional to the weight loss.

Figure 13 shows the variation of DTG and resistivity versus temperature. One can observe that the weight of sample keeps changing during hightemperature treatment. Based on the rate and amount of weight loss, the temperature range of $25 \sim 800{ }^{\circ} \mathrm{C}$ can be divided into three stages: (1) $25{ }^{\circ} \mathrm{C} \sim 300{ }^{\circ} \mathrm{C}$; (2) $300{ }^{\circ} \mathrm{C} \sim 700{ }^{\circ} \mathrm{C}$; (3) $700{ }^{\circ} \mathrm{C} \sim 800{ }^{\circ} \mathrm{C}$. The rate and amount of weight loss becomes progressively larger in these three stages.

The change trend of initial resistivity and the DTG curve at different temperatures in Figure 13 shows a direct proportion relationship between the two parameters of sandstone samples. When the temperature is lower than $300{ }^{\circ} \mathrm{C}$, the change range of the DTG curve is very small in phase 1 , corresponding to the little change of initial resistivity; when the temperature is above $300{ }^{\circ} \mathrm{C}$, the initial resistivity increases rapidly and the change range of the DTG curve becomes larger. A huge peak occurs at approximate $700{ }^{\circ} \mathrm{C}$ in the DTG curve, and a more sharply increase of initial resistivity is accompanied. Hence the variation of resistivity is closely related to the physical and chemical reactions occurring inside the rock at high temperature.

The variations of the above parameters (such as the resistivity, peaking strength, peaking strain, standard deviation of resistivity, porosity) display an abrupt change at around $300{ }^{\circ} \mathrm{C}$, suggesting that it should be a threshold temperature of sandstone. When the temperature exceeds the threshold temperature, the physical and mechanical properties will become poor quickly. In related rock engineering, we should pay more attention to the variation of rock properties before and after the threshold temperature.

\section{CONCLUSIONS}

In order to study the thermal effect of high temperature on rock, the uniaxial compressive 
strength, resistivity, porosity and DTG curves of sandstone samples were measured in a series of experiment. According to the measured results and discussion, main conclusions can be drawn as follows:

1. High temperature leads to irreversible thermal damage of rock. After high-temperature treatment, the uniaxial compressive strength decreases gradually, and the initial resistivity and porosity increase gradually.

2. The relationship of initial resistivity with strength and porosity presents index law. This result can provide the technical basis of a simplefast prediction method for the measurement of mechanical or structural parameters of rock in some rock engineering projects.

3. A threshold temperature of sandstone is found at around $300{ }^{\circ} \mathrm{C}$. When the heating temperature is higher than the threshold temperature, the uniaxial compressive strength decreases quickly, the initial resistivity, porosity and weight loss rate increased rapidly, the discreteness of the variation of resistivity versus stress occurred. This may be caused by the gradual loss of structural water. Besides, the rapid development of micro cracks(caused by the different expansion of minerals) after $300{ }^{\circ} \mathrm{C}$ may lead to this result.

Due to the complexity in the rock structure, we will test the variation in the physical and mechanical properties of the different lithology of rock and the homogeneous rock with different mineral composition which are caused by thermal damage. Deepen the research on changes in microstructure and mineral composition, aim to reveal the thermal damage mechanism of rock and disclose the basic reason in cause the changes of macro parameters.

\section{ACKNOWLEDGEMENTS}

This research was supported by "the Fundamental Research Funds for the Central Universities" (No. 2015XKMS033) and the Priority Academic Program Development of Jiangsu Higher Education Institutions.

\section{REFERENCES}

Binley, A., Henry-Poulter, S. and Shaw, B.: 1996, Examination of solute transport in an undisturbed soil column using electrical resistance tomography. Water Resour. Res., 32(4), 763-769.

Brace, W.F.: 1975, Ditatancy-related electrical resistivity changes in rocks. Pageoph, 113, 207-217. DOI: 10.1007/BF01592911

Chen, D.Y., Chen, F. and He, G.Y.: 1987, Influences of "stress reversal" on rock resistivity during loading procedure. Acta Seis. Sinica., 9(3), 303-311. DOI: 10.1007/BF02652497

Chen, F., An, J.Z. and Liao, C.T.: 2003, Directional characteristic of resistivity changes in rock of original resistivity anisotropy. Chin. J. Geophys., 46(2), 271280.

Ferrero, A.M. and Marini, P.: 2001, Experimental studies on the mechanical behavior of two thermal cracked marbles. Rock Mech. Rock Eng., 34(1), 57-66. DOI: $10.1007 / \mathrm{s} 006030170026$
Guseinov, A.A. and Gargatsev, I.O.: 2005, Electrical conductivity of alkaline feldspars at high temperature. Izv. Phys. Earth, 41(8), 520-523.

Lebedev, T.S. and Shepel, S.I.: 1984, Thermobaric studies of the electric parameters of granitoids. Geofiz. Zh., $6(4), 14-23$.

Li, X.S.: 2008, Experimental study on mechanical properties of grit stone after higer temperature. Jiaozuo: Master Thesis, Henan Polytech. Univ..

Liao, C.T., Chen, F., Wu, M.L. and An, J.Z.: 2003, A new technique for detecting the spreading precursor of underground concealed fracture. Acta Geosci. Sinica., 24(5), 453-458.

Liu, S.D., Wang, B., Zhou, G.Q., Yang, S.L. and Chen, M.J.: 2009, Experimental research on mine floor water hazard early warning based on response of geoelectric field in groundwater seepage. Chin. J. Rock Mech. Eng., 28(2), 267-272.

Mao, T.E., Chen, D.Y., Liu, X.M., Yu, S.R. and Song, D.J.: 1988, Experimental research on change of georesistivity anisotropy of pressed rocks and on the spot observation. Earthquake, 18, 33-38.

Roddy, D.J. and Younger, P.L.: 2010, Underground coal gasification with CCS: a pathway to decarbonising industry. Energy Environ. Sci., 3, 400-407. DOI: $10.1039 / \mathrm{B} 921197 \mathrm{G}$

Rutqvist, J., Wu, Y.S., Tsang, C.F. and Bodvarsson, G.: 2002, A modeling approach for analysis of coupled multiphase fluid flow, heat transfer, and deformation in fractured porous rock. Int. J. Rock Mech. Min. Sci., 39, 429-442. DOI: 10.1016/S1365-1609(02)00022-9

Rzhevskii, V.V., Dobretsov, V.B. and Yamshchikov, V.S.: 1965 , Investigation of the effect of temperature on the physical properties of siderite ores for the purposs of selecting the parameters of low-frequency rock breaking. J. Min. Sci, 1, 116-118. DOI: $10.1007 / \mathrm{BF} 02501937$

Su, C.D., Guo, W.B. and Li, X.S.: 2008, Experimental research on mechanical properties of coarse sandstone after high temperatures. Chin. J. Rock Mech. Eng., 27(6), 1162-1170.

Sun, Q., Zhang, W.Q., Xue, L. et al.: 2015a, Thermal damage pattern and thresholds of granite. Environ. Earth Sci., 74(3), 2341-2349. DOI: 10.1007/s12665015-4234-9

Sun, Q., Zhu, S.Y. and Xue, L.: 2015b, Electrical resistivity variation in uniaxial rock compression. Arab. J. Geosci., 8, 1869-1880. DOI: $10.1007 / \mathrm{s} 12517-014-1381-3$

Sundberg, J., Back, P.E., Christiansson, R., Hokmark, M., Ländell, M. and Wrafter, J.: 2009, Modeling of thermal rock mass properties at the potential sites of a Swedish nuclear waste repository. Int. J. Rock Mech. Min. Sci., 46, 1042-1054.

DOI: $10.1016 /$ j.ijrmms.2009.02.004

Zhan, F. and Cai, M.: 2007, Influence of high temperature on anchoring system of cable bolts at stope hanging wall. J. Liaoning Tech. Univ., 26,524-526.

Zhang, L.Y., Mao, X.B. and Lu, A.H.: 2009, Experimental study of on the mechanical properties of rocks at high temperature. Chin. Ser. E-Tech. Sci., 52(3), 641-646. DOI: 10.1007/s11431-009-0063-y

Zhang, W.Q., Qian, H.T., Sun, Q. and Chen, Y.H.: 2015, Experimental study of the effect of high temperature on primary wave velocity and microstructure of limestone. Environ. Earth Sci., 74, 5739-5748. DOI: $10.1007 / \mathrm{s} 12665-015-4591-4$ 